\title{
Polymorphisms of NRF2 gene correlated with decreased FEV1 in lung cancers of smokers
}

\author{
HIDEFUMI SASAKI, AYUMI SUZUKI, MASAYUKI SHITARA, YU HIKOSAKA, KATSUHIRO OKUDA, \\ SATORU MORIYAMA, MOTOKI YANO and YOSHITAKA FUJII
}

Department of Oncology, Immunology and Surgery, Nagoya City University Graduate School of Medical Sciences, Nagoya, Aichi 467-8601, Japan

Received February 1, 2013; Accepted March 12, 2013

DOI: $10.3892 /$ br.2013.83

\begin{abstract}
The metabolism of xenobiotics plays a fundamental role in smoking-related lung function loss and the development of pulmonary disease. An NRF2-dependent response is a key protective mechanism against oxidative stress. In the present study, we evaluated the effect of single nucleotide polymorphisms in NRF2 genes on the level of forced expiratory volume in one second (FEV1) in lung cancers of smokers. We genotyped the status of NRF2 gene polymorphisms in 209 surgically treated lung cancer cases of smokers using TaqMan polymerase chain reaction (PCR). The results demonstrated the mean FEV1 in patients with $\mathrm{rs} 2364723 \mathrm{C} / \mathrm{C}, \mathrm{C} / \mathrm{G}$ and $\mathrm{G} / \mathrm{G}$ to be 2143.9, 2294.2 and $2335.4 \mathrm{ml}$, respectively, and there was a tendency towards lower FEV1 in $\mathrm{C} / \mathrm{C}$ phenotype $(\mathrm{P}=0.0944)$. The mean FEV1 was significantly lower in the $\mathrm{C} / \mathrm{C}$ phenotype (2143.9 $\pm 566.0 \mathrm{ml})$ compared to $\mathrm{C} / \mathrm{G}$ or $\mathrm{G} / \mathrm{G}(2308.9 \pm 642.9 \mathrm{ml}$, $\mathrm{P}=0.05)$. The mean FEV1 in patients with rs6726395 A/A, $\mathrm{G} / \mathrm{A}$ and $\mathrm{G} / \mathrm{G}$ was $66.7,71.2$ and $72.3 \%$, respectively, and there was a significant difference between $\mathrm{A} / \mathrm{A}$ and $\mathrm{G} / \mathrm{G}$ phenotype $(\mathrm{P}=0.043)$. A tendency towards a lower mean FEV1 in A/A phenotype $(66.7 \pm 11.7 \%)$ was observed when compared to $A / G$ or $\mathrm{G} / \mathrm{G}(71.9 \pm 10.7 \%, \mathrm{P}=0.07)$. This study demonstrated that an NRF2-dependent response to cigarette smoking has the potential to affect FEV1 decrease in a lung cancer population. In conclusion, the results have shown that NRF2 genetic changes may play a role in FEV1 loss in smokers with lung cancer.
\end{abstract}

\section{Introduction}

Cigarette smoking (CS) is the main etiology of chronic obstructive pulmonary disease (COPD) and lung cancer. They share a common environmental risk factor in CS exposure and a

Correspondence to: Dr Hidefumi Sasaki, Department of Oncology, Immunology and Surgery, Nagoya City University Graduate School of Medical Sciences, Kawasumi 1, Mizuho-cho, Mizuho-ku, Nagoya, Aichi 467-8601, Japan

E-mail: hisasaki@med.nagoya-cu.ac.jp

Key words: nuclear factor (erythroid derived 2)-like 2, polymorphism, $\mathrm{NRF} 2$, forced expiratory volume in 1 second, smoker genetic predisposition (1), as indicated by the fact that $15-30 \%$ of smokers developed COPD or lung cancer (2). Fifty to $80 \%$ of lung cancer patients have pre-existing COPD, compared with a $15-20 \%$ prevalence of COPD in the general smoking population (3-5). Findings of previous studies demonstrated that smokers with COPD are at an increased risk for developing lung cancer $(6,7)$. Even a small reduction in forced expiratory volume in one second (FEV1), a marker of airflow obstruction, constitutes a significant predictor of lung cancer (8). Findings of a previous study suggested that in chronic smokers, airflow limitation (or reduced FEV1) is a strongly genetically determined response to CS (9). The contribution of genetic factors to the variance in FEV1 might therefore be much greater than that from CS exposure dose (10).

Nuclear factor (erythroid derived 2)-like 2 (NRF2, gene name designated as NFE2L2), is a master transcriptional activator of genes encoding numerous cytoprotective enzymes that are induced in response to environmental and endogenously derived oxidative/electrophilic agents (11-13). Oxidative stress is able to amplify the inflammatory response and the loss of NRF2 activity in COPD lungs may contribute to the increased susceptibility of COPD patients to lung cancer by regulating the expression of numerous anti-oxidant and detoxifying enzymes, thereby enhancing lung inflammation $(14,15)$. In animal models, NRF2 plays an important role in reducing inflammation associated with elastase-induced emphysema (16). Attenuation of NRF2 due to the downregulation of the NRF2 mRNA has been detected in alveolar macrophages of COPD patients (17). Single-nucleotide polymorphisms (SNPs) in the promoter region of NRF2 gene affect transcriptional activity. Additionally, one of the SNPs is associated with the development of acute lung injury (18). NRF2 gene promoter SNP has been identified to be potentially correlated with carcinogenesis (19). The SNP rs2364723 in the first intron of NRF2 gene has been shown to correlate with a lower FEV1 in a Caucasian population (20). Association between another the NRF2 SNP rs6726395 and smoking status affected the annual decline in FEV1 in a Japanese cohort (21).

To analyze the association between the NRF2 SNPs and FEV1 status in Japanese lung cancer of smokers, we investigated three NRF2 SNPs statuses at the untranslated 5' region using the real-time reverse transcription-polymerase chain reaction (PCR) assay using TaqMan probes. The findings were 
Table I. Clinicopathological data of 209 lung cancer patients.

\begin{tabular}{|c|c|c|c|c|}
\hline \multirow[b]{2}{*}{ Variables } & \multicolumn{4}{|c|}{ NRF2 gene status; rs6721961 } \\
\hline & $\mathrm{CC}$ & $\mathrm{CA}$ & AA & P-value \\
\hline Mean age, years \pm SD & $66.9 \pm 8.3$ & $65.6 \pm 9.5$ & $65.7 \pm 10.2$ & NS \\
\hline \multicolumn{5}{|l|}{ Stage } \\
\hline $\mathrm{I}$ & 67 & 41 & 4 & \multirow[t]{2}{*}{0.0373} \\
\hline II-IV & 47 & 38 & 12 & \\
\hline \multicolumn{5}{|l|}{ Gender } \\
\hline Male & 105 & 70 & 15 & \multirow[t]{2}{*}{0.6505} \\
\hline Female & 9 & 9 & 1 & \\
\hline \multicolumn{5}{|l|}{ Smoking, BI } \\
\hline$\geq 800$ & 43 & 28 & 4 & \multirow[t]{2}{*}{0.6073} \\
\hline$<800$ & 71 & 51 & 12 & \\
\hline \multicolumn{5}{|l|}{ Age, years } \\
\hline$\geq 65$ & 50 & 37 & 11 & \multirow[t]{2}{*}{0.1786} \\
\hline$<65$ & 64 & 42 & 5 & \\
\hline \multicolumn{5}{|l|}{ Pathological subtypes } \\
\hline $\mathrm{SCC}$ & 75 & 48 & 11 & \multirow[t]{2}{*}{0.7186} \\
\hline Non-SCC & 39 & 31 & 5 & \\
\hline \multicolumn{5}{|l|}{ FEV1 } \\
\hline Mean \pm SD & $2201.8 \pm 586.9$ & $2295.7 \pm 633.6$ & $2311.9 \pm 768.0$ & NS \\
\hline \multicolumn{5}{|l|}{$\%$ FEV1 } \\
\hline Mean \pm SD & $71.7 \pm 10.4$ & $71.9 \pm 11.3$ & $68.5 \pm 11.5$ & NS \\
\hline
\end{tabular}

NS, not significant; BI, brinkman index; SCC, squamous cell carcinoma; SD, standard deviation; FEV1, forced expiratory volume in one second, smoker.

compared to the clinicopathologic parameters of the lung cancers.

\section{Patients and methods}

Patients. This retrospective study group included 209 lung cancer patients who had undergone surgery at the Department of Surgery, Nagoya City University Hospital, between 2005 and 2012. The lung tumors were classified according to the General Rule for Clinical and Pathological Record of Lung Cancer (7th edition) in Japan. The samples were immediately frozen and stored at $-80^{\circ} \mathrm{C}$ until assayed. The blood from 10 healthy volunteers was used as a positive control. The institutional ethics board of Nagoya City University approved the study and written consent was obtained from the patients.

The clinical and pathological characteristics of the 209 lung cancer patients were: 113 cases at stage I, 44 at stage II and 52 cases at stage III-IV. The mean age was 66.3 years (range, 33-88). Of the 209 lung cancer patients, 190 (90.9\%) were male and $19(9.1 \%)$ were female. In total, 134 patients were diagnosed as having squamous cell carcinoma.

TaqMan PCR assays for NRF2 gene. Genomic DNA was extracted from peripheral blood samples using the Midi Blood DNA Extraction kit (Qiagen, Tokyo, Japan). Genomic DNA was also extracted from adjacent normal lung tissues using the Wizard ${ }^{\circledR}$ SV Genomic DNA Purification System (Promega, Madison, WI, USA) according to the manufacturer's instructions. DNA concentration was determined by a spectrophotometer and adjusted to a concentration of $10 \mathrm{ng} / \mathrm{ml}$. Three SNPs were analyzed: rs6726395 (A;VIC>G; FAM at first intron, assay ID C_155538_10), rs2364723 (C;VIC>G;FAM at first intron, assay ID C_351878_10) and rs6721961 (-617C>A, G;VIC, T; FAM at promoter region, custom designed). Genotyping was carried out using TaqMan PCR assays (Applied Biosystems, Warrington, UK) in 96-well arrays that included two blank wells as negative controls, according to the manufacturer's instructions. The TaqMan Pre-Designed SNP Genotyping assay and TaqMan MGB probes were used. TaqMan PCR and genotyping analyses were carried out on the Applied Biosystems 7500 Fast Real-Time PCR System. The reaction mixture was amplified in $1 \mu \mathrm{l}$ of template DNA $(10 \mathrm{ng} / \mu \mathrm{l}), 12.5 \mu \mathrm{l}$ of $2 \mathrm{X}$ TaqMan Universal Master Mix, $0.625 \mu \mathrm{l}$ of $20 \mathrm{X}$ primer/probe mix, and $10.875 \mu \mathrm{l}$ of $\mathrm{ddH}_{2} \mathrm{O}$ in a volume of $25 \mu \mathrm{l}$. The cycling conditions were as follows: initial denaturation at $95^{\circ} \mathrm{C}$ for $10 \mathrm{~min}$, followed by 40 cycles at $95^{\circ} \mathrm{C}$ for $15 \mathrm{sec}$ and $58^{\circ} \mathrm{C}$ for $1 \mathrm{~min}$. The results were automatically analyzed on Applied Biosystems 7500 Real Time PCR System using an allelic discrimination assay program. If one of the three SNP statuses were not determined, the case was excluded. Approximately 10 cases were excluded from the criteria. 
Table II. Clinicopathological data of 209 lung cancer patients.

NRF2 gene status; rs2364723

\begin{tabular}{|c|c|c|c|c|}
\hline \multirow[b]{2}{*}{ Variables } & \multicolumn{4}{|c|}{ NRF2 gene status; rs2364723 } \\
\hline & $\mathrm{CC}$ & $\mathrm{CG}$ & GG & P-value \\
\hline Mean age, years $\pm S D$ & $67.1 \pm 8.8$ & $66.2 \pm 9.5$ & $65.2 \pm 8.1$ & NS \\
\hline \multicolumn{5}{|l|}{ Stage } \\
\hline I & 45 & 45 & 23 & \multirow[t]{2}{*}{0.7943} \\
\hline II-IV & 35 & 38 & 23 & \\
\hline \multicolumn{5}{|l|}{ Gender } \\
\hline Male & 73 & 74 & 43 & \multirow[t]{2}{*}{0.7093} \\
\hline Female & 7 & 9 & 3 & \\
\hline \multicolumn{5}{|l|}{ Smoking, BI } \\
\hline$\geq 800$ & 26 & 38 & 11 & \multirow[t]{2}{*}{0.0334} \\
\hline$<800$ & 54 & 45 & 35 & \\
\hline \multicolumn{5}{|l|}{ Age, years } \\
\hline$\geq 65$ & 38 & 34 & 22 & \multirow[t]{2}{*}{0.6386} \\
\hline$<65$ & 42 & 49 & 24 & \\
\hline \multicolumn{5}{|l|}{ Pathological subtypes } \\
\hline $\mathrm{SCC}$ & 51 & 54 & 29 & \multirow[t]{2}{*}{0.9705} \\
\hline Non-SCC & 29 & 29 & 17 & \\
\hline \multicolumn{5}{|l|}{ FEV1 } \\
\hline Mean \pm SD & $2143.9 \pm 566.0$ & $2249.2 \pm 621.9$ & $2335.4 \pm 685.5$ & $\begin{array}{c}\text { CC vs. GG } \\
0.0944\end{array}$ \\
\hline \multicolumn{5}{|l|}{$\%$ FEV1 } \\
\hline Mean $\pm \mathrm{SD}$ & $70.6 \pm 10.4$ & $73.2 \pm 11.5$ & $70.0 \pm 10.1$ & NS \\
\hline
\end{tabular}

NS, not significant; BI, brinkman index; SCC, squamous cell carcinoma; SD, standard deviation; FEV1, forced expiratory volume in one second, smoker.

Statistical analysis. Statistical analyses were performed using the Mann-Whitney U-test for unpaired samples and Wilcoxon's signed-rank test for paired samples. Linear relationships between variables were determined by means of simple linear regression. Correlation coefficients were determined by rank correlation using Spearman's test and the $\chi^{2}$ test. The overall survival of lung cancer patients was examined by the Kaplan-Meier method and differences were examined by the log-rank test. The analysis was carried out using the Stat-View software package (Abacus Concepts, Inc., Berkeley, CA, USA). $P<0.05$ considered to indicate a statistically significant difference.

\section{Results}

The genotyping of NRF2 gene polymorphism in lung cancer of smokers was examined. Using the TaqMan probe sets for rs6721961, the SNP statuses were determined as follows: 114 were CC, 79 were CA and 16 were AA. No correlation was observed between SNP statuses and variables such as age, gender, pathological stages or FEV1. AA patients had more advanced stages when compared to $\mathrm{CC}$ patients $(\mathrm{P}=0.0373)$ (Table I).

Using the TaqMan probe sets for rs2364723, the SNP statuses were determined as follows: 80 were CC, 83 were $\mathrm{CG}$ and 46 were GG. No correlation was noted between SNP statuses and variables including age, gender, pathological subtypes or stages. GG patients had a higher Brinkman index when compared to CC patients $(\mathrm{P}=0.0344)$ (Table II). Mean \pm standard deviation $(\mathrm{SD})$ of FEV1 in patients with rs2364723 C/C, C/G and G/G was 2143.9 $\pm 566.0,2294.2 \pm 621.9$ and $2335.4 \pm 685.5 \mathrm{ml}$, respectively, and there was a tendency towards a lower FEV1 in the $\mathrm{C} / \mathrm{C}$ phenotype $(\mathrm{P}=0.0944)$. The mean FEV1 was significantly lower in the $\mathrm{C} / \mathrm{C}$ phenotype $(2143.9 \pm 566.0 \mathrm{ml})$ compared to that in $\mathrm{C} / \mathrm{G}$ or $\mathrm{G} / \mathrm{G}$ $(2308.9 \pm 642.9 \mathrm{ml}, \mathrm{P}=0.05)$.

Using the TaqMan probe sets for rs6726395, the SNP statuses were determined as follows: 17 were AA, 66 were GA and 126 were GG. There was no correlation between SNP statuses and variables such as age, gender, pathological subtypes or stages (Table III). The mean \% FEV1 in patients with rs6726395 A/A, G/A and G/G was 66.7, 71.2 and 72.3\%, respectively, and there was a significant difference between the $\mathrm{A} / \mathrm{A}$ and $\mathrm{G} / \mathrm{G}$ phenotypes $(\mathrm{P}=0.043)$. There was a tendency towards a lower mean FEV1 in the A/A phenotype $(66.7 \pm 11.7 \%)$ when compared to that of $\mathrm{A} / \mathrm{G}$ or $\mathrm{G} / \mathrm{G}(71.9 \pm 10.7 \%, \mathrm{P}=0.07)$.

The overall survival of 209 lung cancer patients from Nagoya City University, with follow-up through October 31, 2012, was studied in reference to the NRF2 gene polymorphism statuses. None of the three SNPs was identified as 
Table III. Clinicopathological data of 209 lung cancer patients.

NRF2 gene status; rs6726395

\begin{tabular}{|c|c|c|c|c|}
\hline \multirow[b]{2}{*}{ Variables } & \multicolumn{4}{|c|}{ NRF2 gene status; rs6726395 } \\
\hline & AA & GA & GG & P-value \\
\hline Mean age, years \pm SD & $66.7 \pm 8.2$ & $68.0 \pm 8.9$ & $65.4 \pm 8.9$ & NS \\
\hline \multicolumn{5}{|l|}{ Stage } \\
\hline $\mathrm{I}$ & 8 & 39 & 66 & 0.5624 \\
\hline II-IV & 9 & 27 & 60 & \\
\hline \multicolumn{5}{|l|}{ Gender } \\
\hline Male & 16 & 60 & 114 & 0.8868 \\
\hline Female & 1 & 6 & 12 & \\
\hline \multicolumn{5}{|l|}{ Smoking, BI } \\
\hline$\geq 800$ & 3 & 26 & 46 & 0.2427 \\
\hline$<800$ & 14 & 40 & 80 & \\
\hline \multicolumn{5}{|l|}{ Age, years } \\
\hline$\geq 65$ & 8 & 23 & 63 & 0.1320 \\
\hline$<65$ & 9 & 43 & 63 & \\
\hline \multicolumn{5}{|l|}{ Pathological subtypes } \\
\hline $\mathrm{SCC}$ & 12 & 42 & 80 & 0.8447 \\
\hline Non-SCC & 5 & 24 & 46 & \\
\hline \multicolumn{5}{|l|}{ FEV1 } \\
\hline Mean \pm SD & $2132.4 \pm 647.2$ & $2214.2 \pm 615.5$ & $2277.5 \pm 618.6$ & NS \\
\hline \multicolumn{5}{|l|}{$\%$ FEV1 } \\
\hline Mean \pm SD & $66.7 \pm 11.7$ & $71.2 \pm 11.4$ & $72.3 \pm 10.3$ & $\begin{array}{c}\text { AA vs. GG } \\
0.043\end{array}$ \\
\hline
\end{tabular}

NS, not significant; BI, brinkman index; SCC, squamous cell carcinoma; SD, standard deviation; FEV1, forced expiratory volume in one second, smoker.

a prognostic factor (log-rank test, rs6721961, $\mathrm{P}=0.9731$, rs2364723, $\mathrm{P}=0.9120$, rs6726395, $\mathrm{P}=0.0878$ ).

\section{Discussion}

Findings of the present study demonstrated that NRF2 gene SNP statuses were correlated with FEV1 loss. This finding was in agreement with results of recently conducted studies $(20,21)$. Previous studies have documented that in both COPD and lung cancer, environmental factors such as CS interact with multiple polymorphic genes to influence susceptibility to disease. Only a fraction of smokers develop COPD and/or lung cancer (22), suggesting a different individual susceptibility to the risk of COPD and/or lung cancer. Genes involved in the adjustment of oxidant and noxious compounds are likely to be important in gene environment interactions in COPD and lung cancer (23).

Continuous chronic exposure of tissues of the respiratory tract to CS generally confronts cellular defense systems and deposits trigger a pleiotropic adaptive response, aimed at restoring tissue homeostasis. In a recent study, it was suggested that a characteristic of this defense system was caused by the activation of the transcription factor NRF2, consequent to its established role as a master regulator of the cellular antioxidant response (24). NRF2 regulates the expression of several genes encoding antioxidant and detoxification proteins or enzymes $(11,25)$. Differences in the xenobiotic metabolism may contribute to the risk of developing both CODP and lung cancer $(26,27)$. Common somatic mutations in the encoding region of the NRF2 gene resulting in increased cellular accumulation of NRF2 are associated with poor prognosis in squamous cell lung carcinoma $(27,28)$. Exposure of mice to CS enhances oxidative damage and inflammation in the lung thorough disruption of the NRF2 gene (29). Additionally, a significant decrease in the NRF2 protein level has been described in COPD $(14,17)$. This observation suggested that different changes in the NRF2 pathway are involved in the development of COPD and lung cancer.

SNP rs2364723 was reported to associate with the level of FEV1 in the Siedlinski et al (20) cohort. Moreover, SNP rs2364723 is almost identical to the described promoter SNPs (30), suggesting a role in the regulation of NRF2 transcription. The SNPs showed no significant effect on the level of FEV1 in never-smokers, thus the effects provided by NRF2 rs2364723 SNP were more prominent in smokers (20). A stronger effect of the rs6726395 SNP on the annual FEV1 decline was observed in smokers compared to that in never-smokers (21), indicating a gene-smoking interaction in FEV1 decrease. Such an interaction is reasonable as NRF2 activation protects tissues against oxidative stress. Although the rs6726395 is located in the first intron of the NRF2 
gene, the mechanisms mediating the relationship between rs6726395 and FEV1 have yet to be determined (21).

\section{Acknowledgements}

The authors would like to thank Mrs. Yuka Toda for her excellent technical assistance. Grants-in-Aid for Scientific Research were provided by the Japan Society for the Promotion of Science (JSPS) (nos. 24692097, 23659674 and 21591820).

\section{References}

1. Caramori G, Casolari P, Cavallesco GN, Giuffre S, Adcock I and Papi A: Mechanisms involved in lung cancer development in COPD. Int J Biochem Cell Biol 43: 1030-1044, 2011.

2. El-Zein RA, Young RP, Hopkins RJ and Etzel CJ: Genetic predisposition to chronic obstructive pulmonary disease and/or lung cancer: important considerations when evaluating risk. Cancer Prev Res 5: 522-527, 2012.

3. Young RP, Hopkins RJ, Christmas T, Black PN, Metcalf P and Gamble GD: COPD prevalence is increased in lung cancer independence of age, gender and smoking history. Eur Respir J 34: 380-386, 2009.

4. Wilson DO, Weissfeld JL, Balkan A, et al: Association of radiographic emphysema and airflow obstruction with lung cancer. Am J Respir Crit Care Med 178: 738-744, 2008.

5. Young R and Hopkins R: Lung function predicts lung cancer. Eur Respir J 35: 1421-1422, 2010.

6. Mannino DM, Aguayo SM, Petty TL and Redd SC: Low lung function and incident lung cancer in the United States: data from the first National Health and Nutrition Examination Survey follow-up. Arch Intern Med 163: 1475-1480, 2003.

7. Tockman MS, Anthonisen NR, Wright EC and Donithan MG: Airways obstruction and the risk for lung cancer. Ann Inter Med 106: 512-518, 1987.

8. Wasswa-Kintu S, Gan WQ, Man SF, Pare PD and Sin DD: Relationship between reduced forced expiratory volume in one second and the risk of lung cancer: a systematic review and meta-analysis. Thorax 60: 570-575, 2005.

9. Young RP, Hopkins RJ and Eaton TE: Forced expiratory volume in one second: not just a lung function test but a marker of premature death from all causes. Eur Respir J 30: 616-622, 2007.

10. Burrows B, Knudson RJ, Cline MG, et al: Qualitative relationships between cigarette smoking and ventilatory function. Am Rev Respir Dis 115: 195-205, 1977.

11. Itoh K, Chiba T, Takahashi S, et al: An Nef2/small Maf heterodimer mediates the induction of phase II detoxifying enzyme genes through antioxidant response elements. Biochem Biophys Res Commun 236: 313-322, 1997.

12. Rushmore TH and Kong AN: Pharmacogenomics, regulation and signaling pathways of phase I and II detoxifying enzymes. Curr Drug Metab 3: 481-490, 2002.

13. Ngyyen T, Yang CS and Pickett CB: The pathways and molecular mechanisms regulating Nrf2 activation in response to chemical stress. Free Radic Biol Med 37: 433-441, 2004.
14. Malhorta D, Thimmulappa R, Navas-Acien A, et al: Decline in NRF2-regulated antioxidants in chronic obstructive pulmonary disease lungs due to loss of its positive regulator, DJ-1. Am J Respir Crit Care Med 178: 592-604, 2008.

15. Cho HY, Reddy SP and Kleeberger SR: Nrf2 defends the lung from oxidative stress. Antioxid Redox Signal 8: 76-87, 2006.

16. Ishii Y, Ito K, Morishima Y, et al: Transcription factor NRF2 plays a pivotal role in protection against elastase-induced pulmonary inflammation and emphysema. J Immunol 175: 6968-6975, 2005.

17. Suzuki M, Betsuyaku T, Ito K, et al: Down-regulated NF-E2-related factor 2 in pulmonary macrophages of aged smokers and patients with chronic obstructive pulmonary disease. Am J Respir Cell Mol Biol 39: 673-682, 2008.

18. Marzec JM, Christie JD, Reddy SP, et al: Functional polymorphisms in the transcription factor NRF2 in humans increase the risk of acute lung injury. FASEB J 21: 2237-2246, 2007.

19. Arisawa T, Tahara T, Shibata T, et al: Nrf2 gene promoter polymorphism and gastric carcinogenesis. Hepatogastroenterology 55: 750-754, 2008.

20. Siedlinski M, Postma DS, Boer JM, et al: Level and course of FEV1 in relation to polymorphisms in NFE2L2 and KEAP1 in the general population. Respir Res 10: 73, 2009.

21. Masuko H, Sakamoto T, Kaneko Y, et al: An interaction between Nrf2 polymorphisms and smoking status affects annual decline in FEV1: a longitudinal retrospective cohort study. BMC Med Genet 12: 97, 2011.

22. Spitz MR, Wei Q, Dong Q, Amos CI and Wu X: Genetic susceptibility to lung cancer: the role of DNA damage and repair. Cancer Epidemiol Biomarkers Prev 12: 689-698, 2003.

23. Seibold MA and Schwartz DA: The lung: the natural boundary between nature and nurture. Annu Rev Physiol 73: 457-478, 2011.

24. Muller T and Hengstermann A: Nrf2: friend and foe in preventing cigarette smoking-dependent lung disease. Chem Res Toxicol 25: 1805-1824, 2012

25. Shibata T, Ohta T, Tong KI, et al: Cancer related mutations in NRF2 impair its recognition by Keap1-Cul3 E3 ligase and promote malignancy. Proc Natl Acad Sci USA 105: 13568-13573, 2008.

26. Gresner P, Gromadzinska J and Wasowicz W: Polymorphism of selected enzymes involved in detoxification and biotransformation in relation to lung cancer. Lung Cancer 57: 1-25, 2007.

27. Rotunno M, Yu K, Lubin JH, et al: Phase I metabolic genes and risk of lung cancer: multiple polymorphisms and mRNA expression. PLoS One 4: e5652, 2009.

28. Sasaki H, Hikosaka Y, Okuda K, et al: NFE2L2 gene mutation in male Japanese squamous cell carcinoma of the lung. J Thorac Oncol 5: 786-789. 2010

29. Rangasamy T, Cho CY, Thimmulappa RK, et al: Genetic ablation of NRF2 enhances susceptibility to cigarette smoke-induced emphysema in mice. J Clin Invest 114: 1248-1259, 2004.

30. Yamamoto T, Yoh K, Kobayashi A, et al: Identification of polymorphisms in the promoter region of the human NRF2 gene. Biochem Biophys Res Commun 321: 72-79, 2004. 